\title{
Prison needle exchange programs rare despite evidence
}

$\mathrm{C}$ lean needle distribution in prisons is "poor and patchy" around the world, despite evidence that it reduces the spread of infectious diseases and does not increase drug use, an international expert told a panel discussion in Toronto, Ontario.

"There's a big gap between what is being recognized at the UN [United Nations] level and what is going on, on the ground," Heino Stöver, a professor at the University of Applied Sciences in Frankfurt, Germany, recently told an audience at the Dalla Lana School of Public Health.

Although the United Nations Office on Drugs and Crime and the World Health Organization (WHO) both advocate for needle and syringe exchanges for inmates, only 60 prisons out of more than 10000 worldwide have launched programs since Switzerland set up the first one in 1994, said Stöver. Switzerland, Spain, Kyrgyzstan, Moldova, Romania, Portugal and Luxembourg all have needle exchange programs in at least one prison.

Germany ended six of its seven programs in the past decade. "They were politically controversial but not professionally controversial. We have very fine evidence that they were working," said Stöver, who has advocated for prison needle exchanges since he was "a young man ... throwing syringes over the prison walls."

A WHO review of 55 European prison needle exchange programs found no reported increase in drug use and no negative unintended consequences. No needles were used as weapons, for example.

Among Canadian inmates, 30\% of men and $34.9 \%$ of women have contracted hepatitis C, compared to $0.95 \%$ of men and $0.61 \%$ of women in the general population. The figures for inmates are based on Correctional Service of Canada's 2008 statistics, the most recent available, compared with 2007 figures for the general population. For HIV, the rates are $1.7 \%$ (men) and $4.7 \%$ (women), compared to $0.2 \%$ in the Canadian population.

Canada does not offer needle exchange programs in any prison. The absence of such programs is the subject



Although the UN and WHO advocate for needle and syringe exchanges for inmates, only 60 prisons of more than 10000 worldwide have programs.

of a current lawsuit that prisoner, HIV/AIDS and Aboriginal advocacy groups have launched. They hope a successful suit will force federal prisons to implement needle exchanges.

Correctional Service Canada "has a comprehensive anti-drug strategy ... providing needles for illicit drug use run counter to that strategy," spokesperson Melissa Hart writes in an email.

The lawsuit argues that prisoners are entitled to the same standards of essential health care as in the wider community, and that the 200 needle exchange programs available across Canada are part of this essential health package, says Lisa Kerr, a lawyer and academic who studies approaches to incarceration and justice.

In addition, lawyers have pointed to the Canadian Charter of Rights and Freedoms, arguing dirty needles in prisons makes life worse for indigenous people, for women and for people with disabilities, Kerr told the panel in Toronto. Indigenous people, who make up $4 \%$ of the Canadian population, account for $23 \%$ of the prison population.

Current methods of reducing infections have shortcomings. Machines that dispense bleach and condoms, for example, are sometimes located near cameras and prisoners worry about increased surveillance if they use them. The dispensing machines are also frequently empty, said Seth Clarke, the community development coordinator for the Prisoners' HIV/AIDS Support Action Network.

Furthermore, bleach is not $100 \%$ effective in eliminating Hepatitis $\mathrm{C}$, and the "best practice" method of cleaning, rinsing and cleaning again is not pragmatic for the "quite hastily" way prisoners use needles, Clarke said. After all, drug use and tattooing are both illegal in prisons.

In addition to providing needle exchange programs, prison authorities should help rather than punish those with addiction issues, argued Clarke. For example, when a prisoner recently turned in his needle because he wanted to stop using, he was slapped with an institutional charge. "This kind of thing happens all the time," he said.

In a taped interview aired during the presentation, one former prisoner said that inmates construct needles out of "markers, light bulb filaments [and] the inside of a pen tube," and often share them. Injectable drugs are popular, he said, because "it's the biggest bang for your buck."

As to how the drugs are getting into prisons, Clarke answered indirectly, noting that family members and friends often face drug dogs and careful searches but "they're not doing that for staff a lot of the time." - Wendy Glauser, Toronto, Ont.

CMAJ 2013. DOI:10.1503/cmaj.109-4644 